\title{
Effect of Powder Particle Size on the Fabrication of Ti-6Al-4V using Direct Laser Metal Deposition from Elemental Powder Mixture
}

\author{
Xueyang Chen ${ }^{1}$, Lei Yan ${ }^{1}, \mathrm{WeiLi}^{1}$, Frank Liou ${ }^{1}$, and Joe Newkirk ${ }^{2}$ \\ ${ }^{1}$ Department of Mechanical and Aerospace Engineering, \\ Mis souri University of Science and Technology, Rolla, MO 65409 \\ ${ }^{2}$ Department of Materials Science and Engineering, \\ Mis souri University of Science and Technology, Rolla, MO 65409
}

\begin{abstract}
Direct Laser Metal Deposition (LMD) was used to fabricate thin-wall Ti-6Al-4V us ing the powder mixture of Ti-6 wt.\%Al-4 wt.\%V. Scanning electron microscopy (SEM), optical microscopy $(\mathrm{OM})$ and energy dispersive spectroscopy (EDS) were employed to examine the chemical composition and micros tructure of the as-deposited sections. Vickers hardness tests were then applied to characterize the mechanical properties of the deposit samp les which were fabricated using pre-mixed elemental powders. The EDS line scans indicated that the chemical composition of the samples was homogenous across the deposit. X-ray diffraction (XRD) was used for the phase identification. After significant analysis, some differences were observed among two sets of deposit samples which varied in the particle size of the mixing Ti-6wt.\%Al-4wt.\%V powder. It could be found that the set with similar particle number for $\mathrm{Ti}, \mathrm{Al}$ and $\mathrm{V}$ powder made composition much more stable and could easily get industry qualified Ti-6Al-4V components.
\end{abstract}

\section{Introduction}

Laser Metal deposition is an additive manufacturing technique. The applications of this technique include coatings, rapid prototyping, tooling, and refurbishment. As shown in Figure 1, laser deposition uses a focu sed laser beamas a heat source to create a melt poolon an underlying substrate. Powder material is then injected into the melt pool through nozzles. The incoming powder is metallurgically bonded to the substrate upon solidification [1-7]. Conventionally, Direct Laser Deposition (DLD) manufactured parts by adding materials layer by layer using pre-alloyed powder. In the pre-alloyed powder, each individual powder particle has the composition of the desired alloy composition in the final part [8]. But sometimes, it is more flexible to use the mixed elemental powder to develop products. In the elemental powder mixture, each individual powder particle only has the composition of a single element present in the desired final alloy composition, but the blend of the total elemental powder forms the desired final alloy composition [8]. In this study, the material of both powder and substrates is Ti-6Al-4V alloy, which is widely used in the aeros pace industry and especially suitable for laser proces sing. Owing to high cost, this titanium alloy is usually developed by near-net-shape Powder Metallurgy (PM) methods such as laser deposition. Ti-6Al-4V is still classified as one of the extremely difficult-to-machine materials using conventional machining which makes DLD an ideal manufacturing process for the same [9]. 


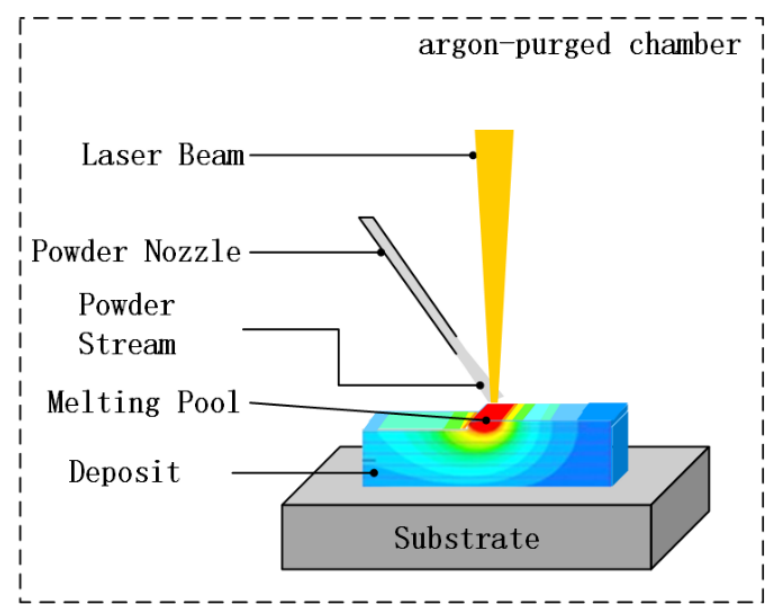

Figure 1. Schematic of the MST-LAMP DLD system[10]

\section{Experimental procedures}

Elemental powders used in this study were titanium, aluminum, and vanadium. The elemental powders were characterized to confirm information provided by suppliers and also to determine particle shape and size. By understanding the size distribution and shape of particles, observations and any findings in deposits could potentially be correlated with particle shape or size. Images were taken using a Hitachi S4700 SEM and image analysis was performed using the Image J software.

Figure 2 shows the SEM images and size distribution of Titanium, Aluminum and Vanadium powder. Titanium powder, grade Ti-109, was purchased from Atlantic Equipment Engineers for use in deposition of Ti-6Al-4V alloys. This powder, grade Ti-109, was listed as being $99.7 \%$ and of -100 mesh $(<149 \mu \mathrm{m})$ size. A SEM micrograph of the titaniumpowder can be seen in Figure 2(a) and indicates significant complexity in particle shape. This makes it difficult for the automatic particle analysis software in ImageJ to accurately outline individual particles and calculate their surface area. While this analysis may not give precise measurements, trends in particle size and distribution can be observed. From the resulting software analysis, an average particle size of $106 \mu \mathrm{m}$ was determined. The elemental aluminum powder, grade Al-103, was produced by Atlantic Equipment Engineers. The purity of the powder was listed as 99.8\%. Using similar software analysis gave the Al-103 an average particle size of $165 \mu \mathrm{m}$. The elemental vanadiumpowder, grade VA-103, was purchased fromthe Atlantic Equipment Engineers with a powder purity of $99.8 \%$. A SEM micrograph of the vanadiumpowder can be seen in Figure 2(c) and the average size of this powder was $175 \mu \mathrm{m}$. 


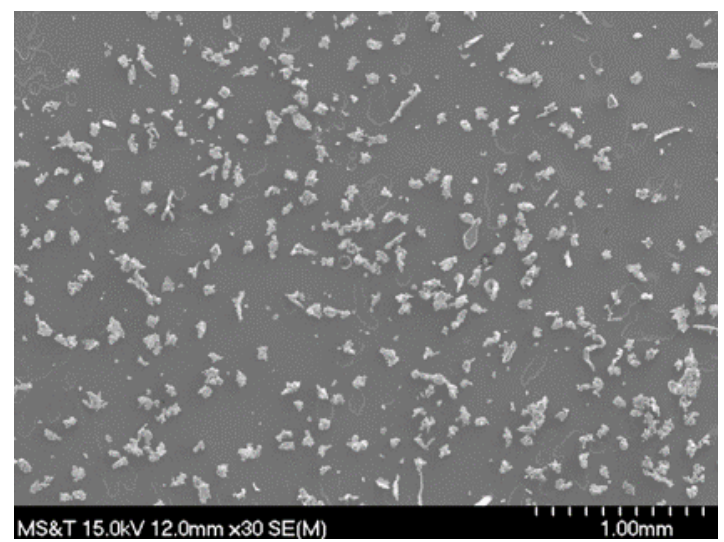

a) Titanium powder SEM image

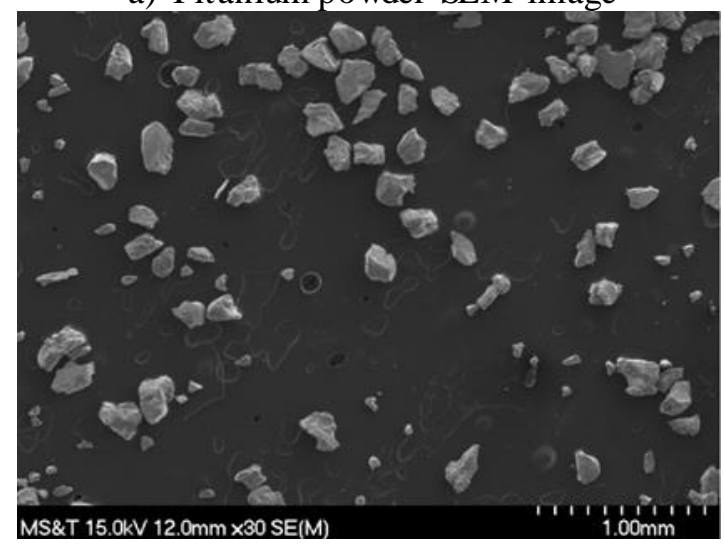

c) Vanadium powder SEM image

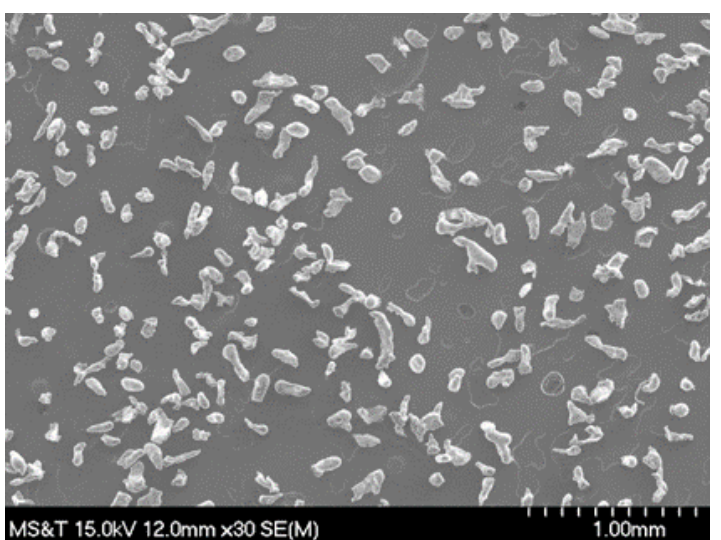

b) Aluminum powder SEM image

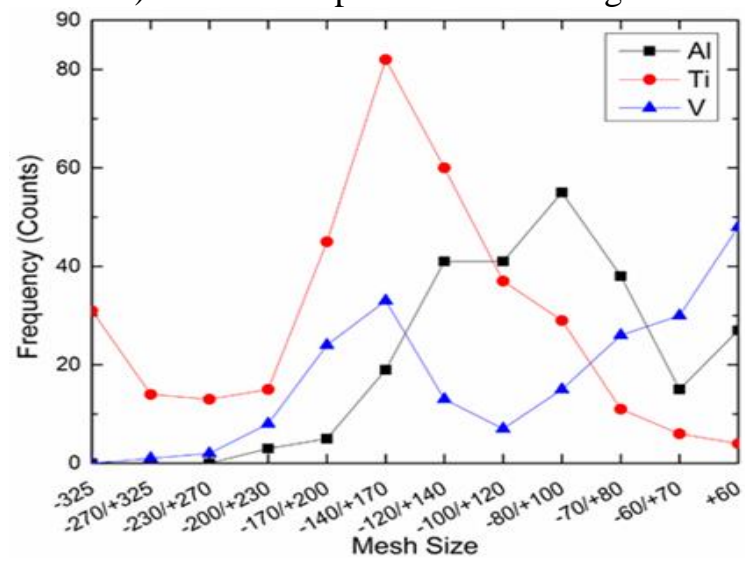

d) Particle size distribution

Figure 2. The SEM images and size distribution of Titanium, Aluminumand Vanadium powder [10]

Before the deposition process began, the elemental powder mixes were prepared. Powders were weighed out according to desired alloy composition in a glove box under an argon atmos phere and placed in a sealed bottle. The powder mixture was a representative of the Ti-6Al$4 \mathrm{~V}$ alloy. After the desired composition was obtained, the bottle was placed in a Turbula ${ }^{\circledR}$ mixer for 20 minutes. A $1 \mathrm{KW} \mathrm{Nd:Yag} \mathrm{laser} \mathrm{was} \mathrm{used} \mathrm{in} \mathrm{this} \mathrm{study} \mathrm{to} \mathrm{deposit} \mathrm{these} \mathrm{elemental} \mathrm{alloy}$ powders. The laser has a wavelength of $1024 \mathrm{~nm}$ and approximate $1 \mathrm{~mm}$ spot size at a $750 \mathrm{~mm}$ focal length. To ensure uniformity, thin wall samples with $30 \mathrm{~mm}$ track length were deposited on Ti-6Al-4V substrates during the study. Also, all the substrates were 2 inches long, 0.5 inch wide, and 0.25 inch thick. Before deposition, a preheating process was performed by using the laser across the surface of the substrate with $1 \mathrm{~kW}$ power and without powder. The preheating process was used to form a melt pool on the substrate and clean the surface of the substrate off of scale buildup and other impurities and surface imperfections. This research theorizes that this pre-heat and clean-up will enable conductive metallurgical bonding of the powders with the substrates.

The commercially irregular pure $\mathrm{Ti}, \mathrm{Al}$, and $\mathrm{V}$ powders were weighed out and two sets of powder blends were prepared to facilitate similar particle acceleration and similar particle number. It is believed that this will enable a relatively uniform shape of the deposit from top to bottom 
using the laser deposition system. $\mathrm{Ti}, \mathrm{Al}$, and $\mathrm{V}$ powders were mixed with the designated weight percentage ratio of 90:6:4 to get target material Ti-6Al-4V. Laser trans verse speed was set at 1000 $\mathrm{mm} / \mathrm{min}$ for all the paths. For laser power, the high normal value of $1 \mathrm{~kW}$ was first selected to generate melt pool and then laser power was dropped to and kept stable at $450 \mathrm{~W}$ (after 10 layers) to maintain a stable melt pool. While depositing the material, uniformity was ensured in the deposition parameters of travel speed, powder feed rate, and layer thickness constant fromtest to test. This would lead to an unbiased comparis on between different depositions by using similar powder particle and similar powder particle number. Using the analysis, the research theorizes that optimized parameters can be determined in the results for different deposits.

During the laser deposition process, powder blends with the designated weight percentage ratio were injected into the melt pool through the nozzle. To confirm to get target material with the original weight percentage ratio, each element in the blend with the desired composition needs to be melted at the same time. The powder particles had the same initial speed when they went into the nozzle. So particle acceleration is a key factor for composition control. According to the fluid mechanics [11], the particle acceleration is inversely proportional to the particle density and the square of powder diameter, which could be expressed as $a \propto 1 /\left(\rho * D^{2}\right)$. Also, particle size for each element in powder blend has a relationship with the particle number. So particle size of each element could be changed to control the composition in the final part. Then the hypothesis proposed in this research is proved using experiments design around two sets of data namely

Set 1: A comparative study of the acceleration of the elemental powder particles (Table 1).

Set 2: A comparative study of the number of particles in each elemental powder (Table 2).

Among the two sets of experiments conducted, the appropriate particle size of $\mathrm{Ti}, \mathrm{Al}$ and $\mathrm{V}$ powder has been selected according to the particle diameter listed in Table 1, it shows the particle size and calculated acceleration ratio of $\mathrm{Ti}, \mathrm{Al}$ and $\mathrm{V}$ powder. In this experiment, $\mathrm{Ti}, \mathrm{Al}$, $\mathrm{V}$ elemental powder has the similar particle acceleration during the process. Similarly, after choosing suitable particle size for set 2, corres ponding particle number ratio of $\mathrm{Ti}, \mathrm{Al}, \mathrm{V}$ powder could be calculated in Table 2 . In this set, $\mathrm{Ti}, \mathrm{Al}, \mathrm{V}$ elemental powder has the similar particle number during the process. These two sets of experiments were chosen to study which factor, among particle acceleration and particle number, would affect an as-built part's final chemistry composition.

Table 1. Particle Size and Acceleration Ratio in Set 1

\begin{tabular}{|c|c|c|}
\hline Irregular powder & Diameter & Acceleration ratio \\
\hline $\mathrm{Ti}$ & 112 & 1 \\
\hline $\mathrm{Al}$ & 133 & 1.18 \\
\hline $\mathrm{V}$ & 96 & 1.06 \\
\hline
\end{tabular}

Table 2. Particle Size and Number Ratio in Set 2

\begin{tabular}{|c|c|c|}
\hline Irregular powder & Diameter & Number ratio \\
\hline $\mathrm{Ti}$ & 147 & 1 \\
\hline $\mathrm{Al}$ & 94 & 0.43 \\
\hline $\mathrm{V}$ & 63 & 0.44 \\
\hline
\end{tabular}


After deposition, longitudinal samples were cut off using the EDM machine and mounted for grinding and polishing. Kroll's Reagent consisting of $92 \mathrm{ml}$ distilled $\mathrm{H} 2 \mathrm{O}, 6 \mathrm{ml} \mathrm{HNO}$, and 2 $\mathrm{ml} \mathrm{HF}$ was used for etching. To research the microstructure characteristic and composition in the elemental powder deposits, energy dispersive spectroscopy (EDS) line scans were performed using Hitachi S4700 and FEI Helio 600 scanning electron micros cope (SEM). Also, optical microscopy was used to assess the microstructure in the samples. Comparison of the mechanical properties between the two sets of different samples was also conducted. The Vickers hardness measurements were taken with a Struers Duramin micro-hardness tester. $9.8 \mathrm{~kg}$ load with a dwell time of 10 seconds was applied during the test hardness procedures.

\section{Results and discussion}

\subsection{Vickers hardness \& EDS test}

Figure 3 shows the composition distribution and Vickers hardness of the deposited sample from elemental powders of Set 1 whose three elements of Ti, $\mathrm{Al}$ and $\mathrm{V}$ have the similar particle acceleration. Ti-6Al-4V substrate Vickers hardness was first taken near the bottom edge that is away from heat affected zone (HAZ) and found to be $352.44 \pm 15.41 \mathrm{HV}$. It was observed that the Vickers hardness values increased as it progressed into the HAZfrom the substrate. In the deposit zone, there was a temporary increase for the first several layers, then a decrease and stabilization from the middle to the top of the deposit.

For the deposited samples using mixed powder of Set 1, area scan and line scan were employed to investigate the composition dis tribution along the build height direction. Figure 3 shows the EDS result of the deposit. The weight percentage of Ti, Al and V could be found in the image in the left figure of Figure 3. Al and V curves were focused on and showed their weight percentage variation against the position in the image on the right. Two marked zones in this figure mean industry qualified $\mathrm{Al}$ and $\mathrm{V}$ weight percentage for Ti-6Al-4V, which is $\mathrm{Al}$ ranges from 5.5$6.75 \%$ and $\mathrm{V}$ ranges from 3.5-4.5\%. At deposit height, $\mathrm{Al}$ and $\mathrm{V}$ weight percentage showed that the values varied outside the qualified range, which means the as-deposit alloy was not the targeted material Ti-6Al-4V. There was some powder loss when the powder mixture went through the nozzle, so it was supposed that les s powder in the blend es pecially for $\mathrm{Al}$ and $\mathrm{V}$ powder because of the low volume of them. This would lead to the result that the weight percentage of Al and $\mathrm{V}$ along build height direction vary a lot. 

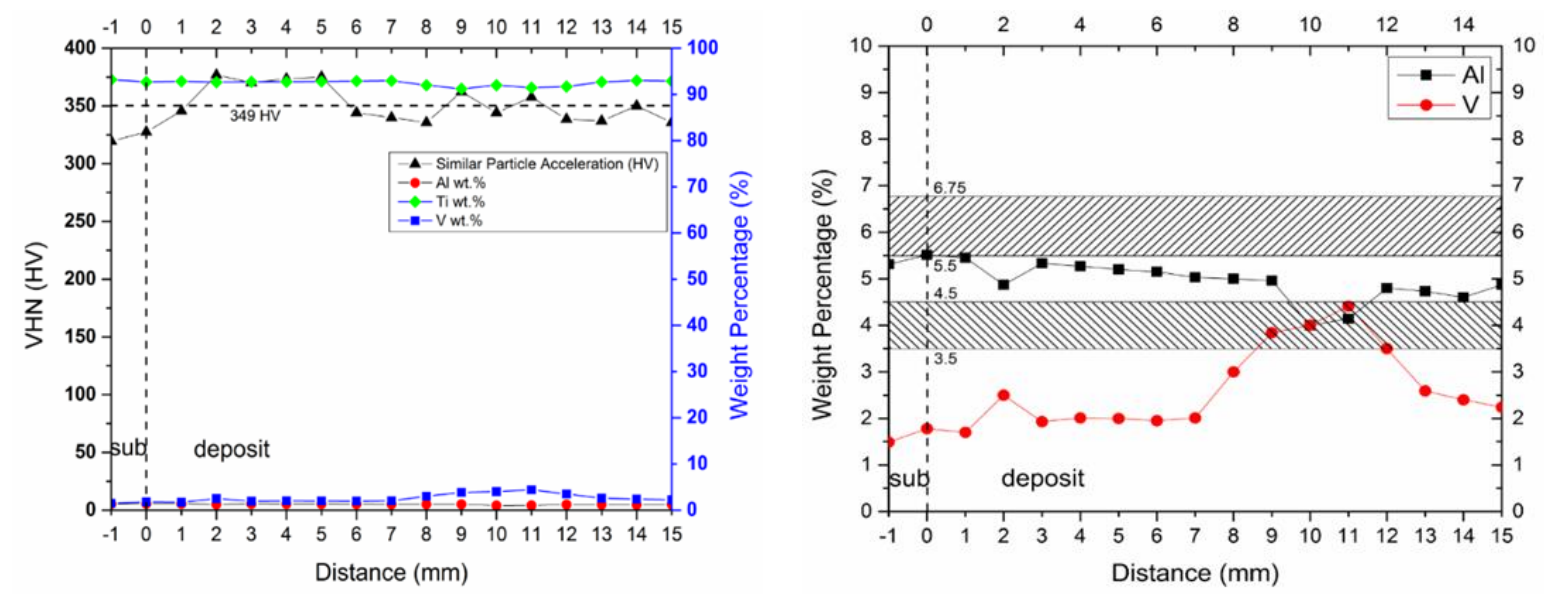

Figure 3. Composition distribution \& Vickers Hardness along build height direction of Set 1

Figure 4 shows the composition distribution and Vickers hardness of the deposited sample from elemental powders of Set 2 whose three elements of Ti, Aland Vhave similar particle number. Also, Ti-6Al-4V subs trate Vickers hardness was first taken near the bottomedge that is away from heat affected zone (HAZ) and found to be $359.11 \pm 13.78 \mathrm{HV}$. In this case, it was observed that the Vickers hardness values decreased with progress into the HAZ from the substrate side. In the deposit zone, there was an increase for the first several layers and stabilization beyond that.

For the newly deposited samples using mixed powder (Set 2), area scans and line scans were also employed to check the composition dis tribution along the build height direction. Figure 4 shows the EDS results of the deposits. The weight percentage of Ti, Al and V could be found in the image on the left of Figure 4. Al and V curves were focused on and showed their weight percentage variation in the image on the right of Figure 4. Two marked zones in the right figure mean industry qualified $\mathrm{Al}$ and Vweight percentage for Ti-6Al-4V. It can be seen that the deposit had qualified $\mathrm{Al}$ and $\mathrm{V}$ weight percentage and get close to the maximum limit of industry qualified Ti-6Al-4V, which means industry qualified Ti-6Al-4V has been made. From this, it can be concluded that powder number for each of the elements in the blends is a key factor towards the composition acquired in the final part. It could be found that similar particle number made composition much more stable and close to industry qualified Ti64. The research theorizes that the increase in the volume of $\mathrm{Al}$ and $\mathrm{V}$ in the set 2's powder blends increases the probability of those two elements particles falling into melt pool. 

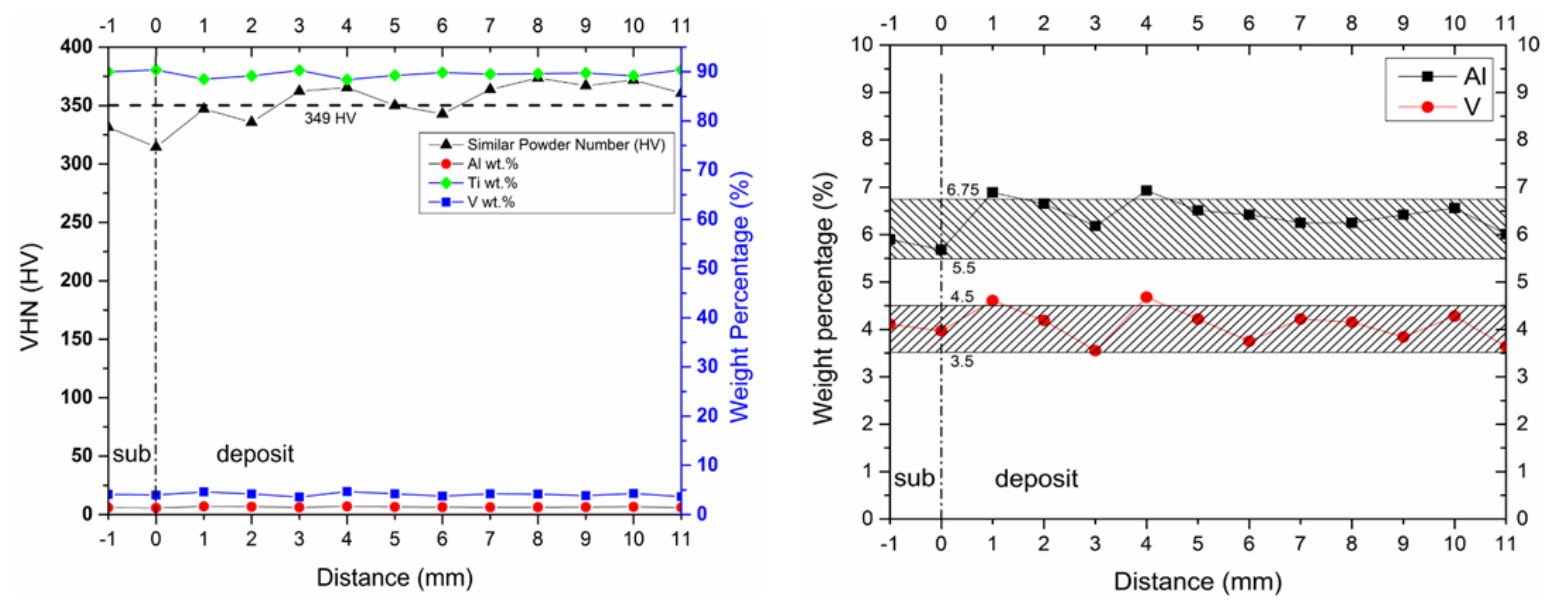

Figure 4. Composition distribution \& Vickers Hardness along build height direction of Set 2

Figure 5(a) showed the line scan of the deposited sample fromelemental powders of Set 1 whose three elements of Ti, Al and V have similar particle acceleration. Figure 5(b) showed the line scan of the deposited sample fromelemental powders of Set 2 whose three elements of Ti, Al and $\mathrm{V}$ have similar particle number. Line scan was shown in Figure 5(a) to define composition homogeneity along the build height direction. Thus, it can be known that similar particle acceleration could not guarantee a homogeneous chemistry dis tribution throughout the deposit from Figure 5(a). Also, Line scan was shown in Figure 5(b) to define composition homogeneity along the build height direction which shows that the dis tribution is homogenous for the deposit.

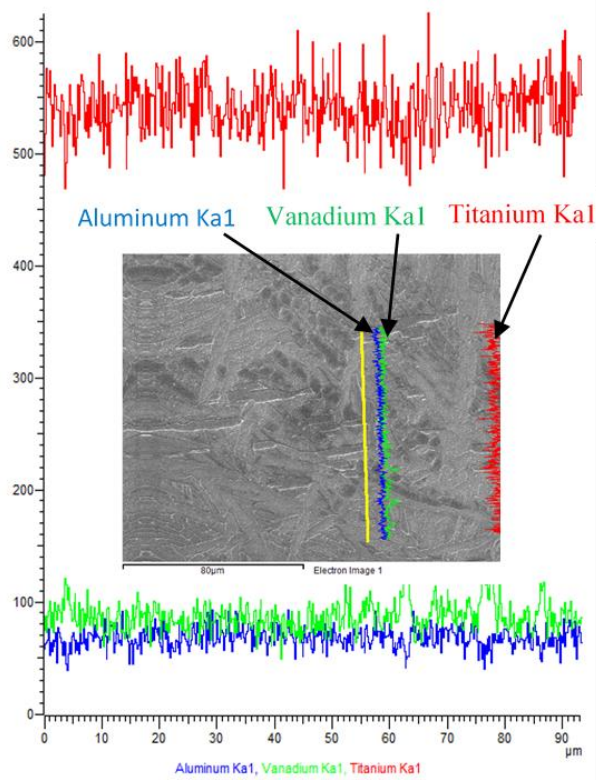

a) Similar particle acceleration

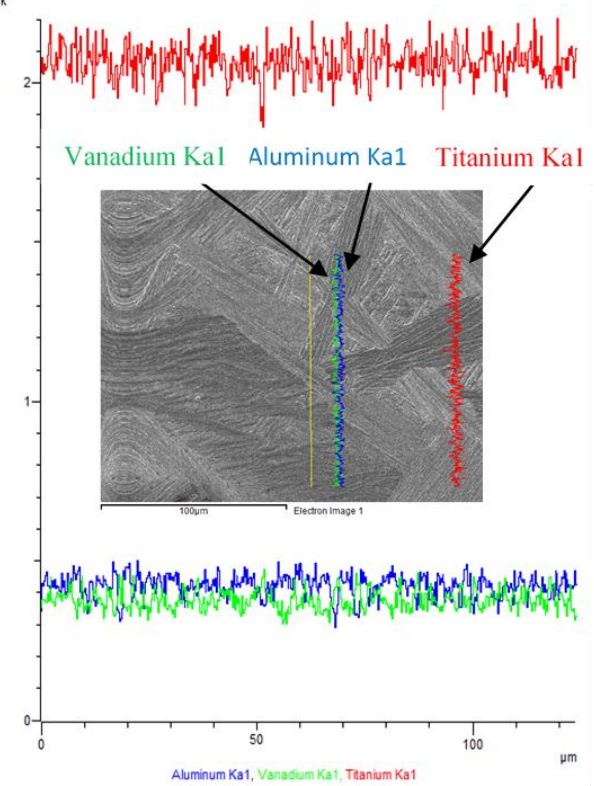

b) Similar particle number

Figure 5. Line scan of the deposited samples 


\subsection{Microstructure}

Figure 6 shows the micros tructure of deposited Ti-6Al-4V from elemental powder mixture with the similar particle acceleration at the same laser power and laser transverse speed. The optical micros cope images captured from the bottom part, middle part and top part of the melt pool (Figure 6 (a) to (c)) in the deposit contained basketwave, colony and martensite micros tructure respectively. Figure 6(a) showed the finer micros tructure could be observed in the bottompart compared with the middle and top part of the deposit. Also, a steady state could be observed frommiddle part to top part and there were limited differences in the microstructure between them. In these two zones, the Widmanstätten Basketwave is the main type of microstructure that could be found. It tends to form with an increasing cooling rate from the $\beta$-phase field [12-13].

Analyses of these microstructures revealed that the smaller grain sizes were achieved closer to the substrate in the deposit. The reason was the proximity to the substrate, increased the cooling rate, which would lead to a finer microstructure [14]. The same phenomenon was observed in the microstructure of the deposited samples from the elemental powder mixture with the similar particle number of Set 2 . Therefore, it was concluded that the steady state section tends to have the lower cooling rate, which would lead to the formation of coarser microstructure [15]. Figure 7 shows the microstructure of deposited Ti-6Al-4V from elemental powder mixture with the similar particle number using the same laser power and laser transverse speed. Also, a steady state could be observed from middle part to top part and Widmanstätten Basketwave is the main type of microstructure that could be found.

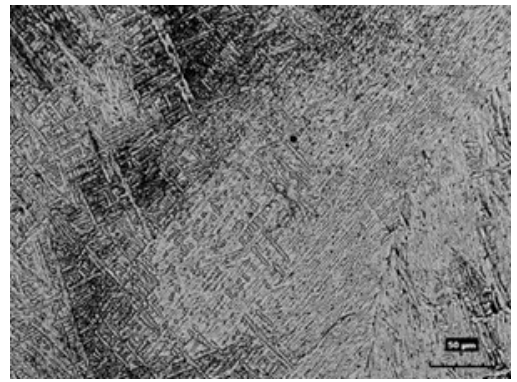

a) Bottom of the deposit

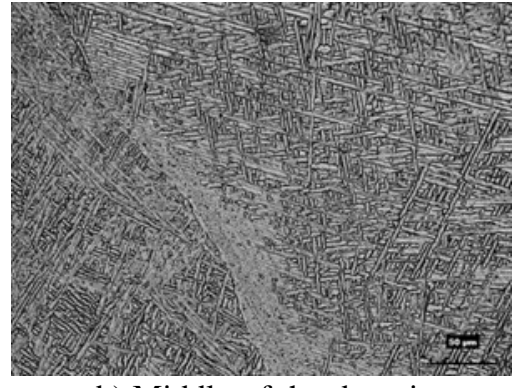

b) Middle of the deposit

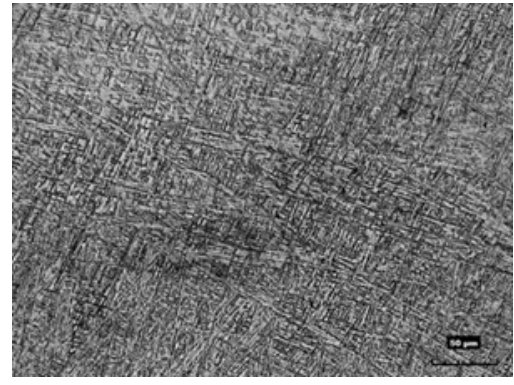

c) Top of the deposit

Figure 6. Microstructure of the deposits using elemental powders of Set 1

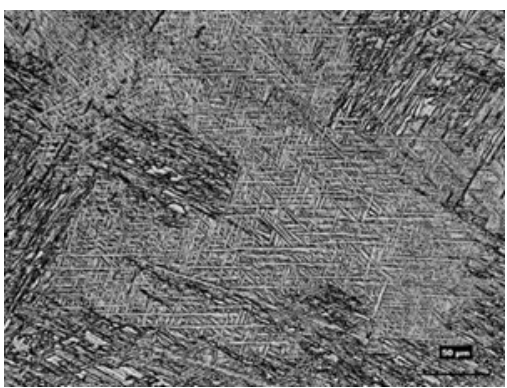

a) Bottom of the deposit

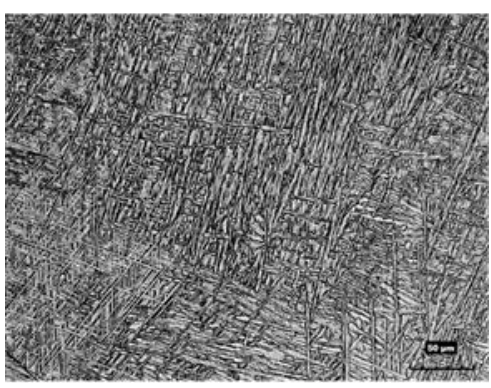

b) Middle of the deposit

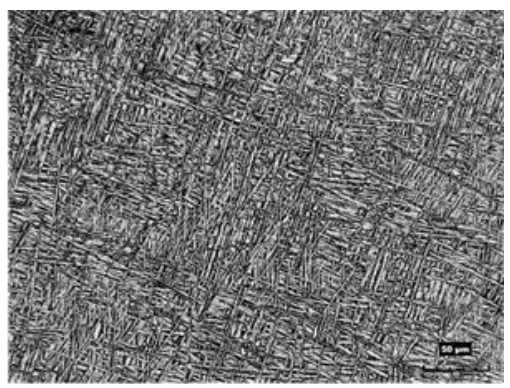

c) Top of the deposit

Figure 7. Microstructure of the deposits using elemental powders of Set 2 


\section{Conclusions}

The blended elemental powder can be used in the direct laser deposition process to offer a variety of cost-effective possibilities for near-net-shape manufacture and functionally graded materials. The finer microstructure could be observed in the bottompart of the deposit compared with the steady state in the middle and top part of the deposit. The Vickers hardness could fluctuate at the first several layers of the deposit and then stayed stable at the top layers of the deposit. Particle number for each element in powder blends is a key factor for composition control in the final part. Similar particle number for $\mathrm{Ti}, \mathrm{Al}$ and $\mathrm{V}$ powder could easily get industry qualified $\mathrm{Ti}$ 6Al-4V components.

\section{References}

[1] Chua, C.K., Leong, K.F., Lim, C.S., Rapid Prototyping:Principles and Applications, 3rd Edition, 2010.

[2] Unocic, R.R. \& DuPont, J.N., Composition control in the direct laser deposition process, Metall. Mater. Trans., 34B, pp.439-445, 2003.

[3] Gedda, H., Kaplan, A. \& Powell, J., Melt-solid interactions in laser cladding and laser casting, Metall. Mater. Trans., 36B, pp. 683-689, 2005.

[4] Lei, T. C., Ouyang, J. H., Pei, Y. T. \& Zhou, Y., Microstructure and sliding wear properties of laser clad TiN reinforced composite coating, Surface Engineering, 12, pp.55-60, 1996.

[5] Kaplan, A.F.H. \& Groboth, G., Process analysis of laser beamcladding, Trans. ASMEJ. Manuf. Sci. Eng., 123, pp.609-614, 2001.

[6] Watkins, K. G., Achieving the potential of direct fabrication with lasers, Proc. of 3rd Int. Conf. on Laser Assisted Net Shaping, Erlangen, Germany, pp. 25-38, 2001.

[7] Griffith, M.L. et al., Understanding thermal behaviour in the LENS process, Materials and Design, 20, pp.107-113, 1999.

[8] Clayton, Rodney Michael, The use of elemental powder mixes in laser-based additive manufacturing, 2013.

[9] O.M. Ivasishin, V.M. Anokhin, A.N. Demidik, D.G. Savvakin, Cost-Effective Blended Elemental Powder Metallurgy of Titanium Alloys for Transportation Application, 2000.

[10] Lei Yan, Xueyang Chen, Wei Li, Frank Liou, and Joe Newkirk, Direct Laser Deposition of Ti-6Al-4V from Elemental Powder Blends, Proceedings of the Solid FreeformFabrication, University of Texas, Austin, 2015.

[11] P.M. Whelan, M.J. Hodgeson (1978). Es sential Principles of Physics (2nd ed.).

[12] R. Boyer: Metals Handbook: Metallography and Microstructures, ASM, Materials Park, OH, 1985, vol. 9, pp.458-75.

[13] Bernd Baufeld., Omer Van der Biest., Rosemary Gault, Additive manufacturing of Ti-6Al$4 \mathrm{~V}$ components by shaped metal deposition: Microstructure and mechanical properties, Materials \& Design, Volume 31, Pages S106-S111, 2010.

[14] Simonelli, M., Y. Y. Tse, and C. Tuck., Microstructure of Ti-6Al-4V produced by selective laser melting, Journal of Physics: Conference Series. Vol. 371. No. 1. IOP Publish ing, 2012.

[15] Nas sar, Abdalla R., and Edward W. Reutzel., Additive Manufacturing of Ti-6Al-4V Using a Pulsed Laser Beam, Metallurgical and Materials Transactions A46.6 (2015): 2781-2789. 